\title{
EFFORTS TO IMPROVE TEACHERS' ABILITIES IN APPLYING CONTEXTUAL LEARNING THROUGH FOCUS GROUP DISCUSSION
}

\author{
Bakri Melpi \\ SDN 019 Sungai Gantang Kuala Rumbai Desa Sungai Gantang, Kempas, Indragiri Hilir, Indonesia \\ bakrimelpi@gmail.com
}

\begin{abstract}
This research was motivated by the learning process which was still dominated by the teacher as a source of knowledge through conventional methods in the form of lecturing; as a result, students became passive during the learning process. Ideally, learning should be able to increase students understanding about the material and their understanding about the relationship between the material and the student's environment. Referring to these problems, it was necessary to apply a method that helped teachers to improve the learning quality. It was hoped that focus group discussions improved the teachers' ability to apply contextual learning. This research was a classroom action research. The research was carried out on teachers at SDN 019 Sungai Gantang from February to March 2020. The research subjects were 17 teachers and the instrument was an observation sheet. The results showed that the teachers' ability to implement contextual learning through focus group discussions increased from $80.25 \%$ (with Good category) in cycle I to $84.45 \%$ (with Very Good category) in cycle increased II. Based on the results of this research, it was concluded that focus group discussions improved teachers' ability in implementing contextual learning.
\end{abstract}

Keywords: teacher's ability, contextual, focus group discussion

\section{UPAYA MENINGKATKAN KEMAMPUAN GURU DALAM MENERAPKAN PEMBELAJARAN KONTEKSTUAL MELELAUI FOCUS GROUP DISCUSSION}

\begin{abstract}
ABSTRAK
Penelitian ini dilatarbelakangi oleh proses pembelajaran di kelas yang masih didominasi oleh guru sebagai sumber pengetahuan melalui metode konvensional berupa ceramah sehingga siswa menjadi pasif dalam pembelajaran. Pembelajaran sebaiknya mampu meningkatkan pemahaman siswa terhadap materi yang dipelajari dan memahami keterkaitan materi dengan lingkungan siswa. Mengacu pada permasalahan tersebut maka perlu diterapkan sebuah metode agar guru dapat meningkatkan kualitas pembelajaran. Melalui focus group discussion diharapkan dapat meningkatkan kemampuan guru dalam menerapkan pembelajaran kontekstual. Jenis penelitian ini adalah penelitian tindakan kelas. Pelaksanaan penelitian dilakukan pada guru SDN 019 Sungai Gantang pada bulan Februari sampai Maret 2020. Subjek penelitian sebanyak 17 guru. Instrumen penelitian berupa lembar observasi. Hasil penelitian menunjukkan bahwa kemampuan guru dalam menerapkan pembelajaran kotekstual melalui focus group discussion pada siklus I memperoleh nilai rata-rata $80.25 \%$ dengan kategori baik, pada siklus II meningkat menjadi $84.45 \%$ dengan kategori baik sekali. Kesimpulan berdasarkan hasil penelitian adalah melalui focus group discussion dapat meningkatkan kemampuan guru dalam menerapkan pembelajaran kontekstual.
\end{abstract}

Kata Kunci: kemampuan guru, kontekstual, focus group discussion

\begin{tabular}{|c|c|c|}
\hline Submitted & Accepted & Published \\
\hline 21 Mei 2021 & 19 Juli 2021 & 28 Juli 2021 \\
\hline
\end{tabular}

\begin{tabular}{|l|l|l|l|}
\hline Citation & $:$ & Melpi, B. (2021). Efforts to Improve Teachers' Abilities in Applying Contextual Learning through Focus Group Discussion. \\
\hline
\end{tabular} Jurnal PAJAR (Pendidikan dan Pengajaran), 5(4), 1037-1042. DOI : http://dx.doi.org/10.33578/pjr.v5i4.8173.

\section{PENDAHULUAN}

Mutu pendidikan dapat ditingkatkan dengan cara meningkatkan proses pembelajaran dan dalam upaya meningkatkan mutu pendidikan tak lepas dari komponen yang terlibat dalam pembelajaran di kelas (Agung, 2015). Salah satu komponen tersebut adalah guru, akan lebih baik jika guru memiliki strategi dalam pembelajaran dan memberikan kesempatan pada siswa untuk agar siswa dapat memahami dan mengingat materi yang disampaikan oleh guru (Nataliya, 2015).
Komponen- komponen dalam pembelajaran meliputi guru, siswa, materi pelajaran, alat dan media pembelajaran, strategi dan model pembelajaran, serta sistem evaluasi hasil belajar. (Suryani, 2016).

Dari komponen tersebut, selain siswa sebagai penerima tindakan pembelajaran, faktor guru sebagai pengelola pembelajaran juga sangat menentukan keberhasilan belajar siswa. Pada proses pembelajaran, guru hendaknya mampu 
menerapkan model pembelajaran yang tepat sehingga siswa memiliki motivasi yang lebih untuk belajar, aktif dalam kegiatan belajar, dan dapat meningkatkan hasil belajar (Suharso, 2017).

Guru sebagai agen dalam kegiatan pembelajaran harus mempunyai kemampuan dalam menerapkan model pembelajaran. Pembelajaran yang dilakukan tidak hanya menyampaikan materi pada siswa melainkan membimbing siswa untuk dapat melakukan kegiatan belajar sehingga siswa memahami apa yang mereka pelajari dan bermanfaat bagi kehidupannya sehari-hari. Salah satu pendekatan yang dapat memfasilitasi kebutuhan tersebut adalah pendekatan kontekstal (Contextual Teaching and Learning) yang merupakan konsep belajar yang menghadirkan situasi dunia nyata ke dalam kelas dan mendorong siswa membuat keterkaitan antara pengetahuan yang dimilikinya dengan penerapannya dalam kehidupan mereka sebagai makhluk sosial di lingkungannya (Nurhadi dalam Siregar, 2018).

Namun pada kenyataan di lapangan, masih terdapat guru yang menggunakan pembelajaran konvensional dalam hal ini cenderung ceramah. Siswa menjadi pasif karena hanya mendengar sembari mencatat penjelasan penting dari guru. Alasan yang banyak dikemukakan adalah sulitnya mengatur waktu karena siswa sulit dikondisikan dalam kegiatan belajar di kelas, sulitnya menyediakan bahan ajar yang menarik dengan alasan keterbatasan alat dan bahan, serta minimnya sarana dan prasarana sekolah yang dapat mendukung kegiatan pembelajaran di kelas. Alasan tersebut menjadikan guru lebih memilih metode ceramah dibanding metode lainnya berdasarkan hasil wawancara dengan guru-guru.

Melihat kendala yang ada, peneliti berupaya melakukan pembinaan agar dapat meningkatkan kemampuan guru. Salah satunya adalah melalui teknik Focus Group Discussion. Secara sederhana, FGD dapat didefinisikan sebagai suatu diskusi yang dilakukan secara sistematis dan terarah mengenai suatu isu atau masalah tertentu (Siregar, 2018). Menurut Irwanto (2006) FGD merupakan suatu proses pengumpulan data dan informasi yang sistematis mengenai suatu permasalahan tertentu yang sangat spesifik melalui diskusi kelompok.

Berdasarkan uraian tersebut, peneliti tertarik melakukan penelitian tindakan dengan judul upaya meningkatkan kemampuan guru dalam menerapkan pembelajaran kontekstual melalui focus group discussion pada SDN 019 Sungai Gantang. Diharapkan melalui penelitian ini guru dapat menerapkan pembelajaran yang bermakna bagi siswa dalam hal ini adalah pembelajaran kontekstual. Guru dapat mengaitkan pembelajaran yang diberikan pada siswa terhadap kaitannya dengan lingkungan sehari-hari siswa.

\section{KAJIAN TEORETIS \\ Pembelaran Kontekstual}

Pembelajaran kontekstual dalam Muslich (2009) dan Heldanengsih (2020) adalah konsep belajar yang membantu guru mengaitkan antara materi pelajaran dengan situasi dunia nyata siswa, dan mendorong siswa membuat hubungan antara pengetahuan yang dimilikinya dengan penerapannya dalam kehidupan sehari-hari. Melalui pembelajaran kontekstual diharapkan siswa dapat lebih memahami pelajaran karena pembelajaran dikaitkan dengan masalah dalam kehidupan siswa.

Model pembelajaran kontekstual dapat mendorong siswa secara aktif terlibat dalam pembelajaran (Hidayah, 2020). Karena dalam pembelajaran kontekstual melibatkan tujuh komponen utama pembelajaran efektif, yakni: konstruktivisme (constructivism), bertanya (questioning), menyelidiki (inquiry), masyarakat belajar (learning community), pemodelan (modelling), refleksi (reflection), dan penilaian autenik (autenthic assessment) (depdiknas dalam Bala, 2018).

\section{Focus Group Discussion}

Sesuai namanya, pengertian focus group discussion (FGD) mengandung tiga kata kunci, yaitu: 1) discussion yang berarti diskusi, diskusi bukan wawancara atau obrolan; 2) group yang berarti kelompok, bukan individual; dan 3) focus yang berarti fokus / terarah bukan bebas (Siregar, 2018). Hal ini berarti bahwa pembicaraan yang dilakukan bukan sekedar berkumpul secara 
berkelompok untuk membicarakan sesuatu melainkan membahas suatu hal secara terarah untuk dapat mencapai tujuan yang diharapkan, dalam hal ini adalah kemampun guru dalam menerapkan pembelajaran kontekstual.

Kegiatan dalam diskusi, guru membahas permasalahan yang sedang dihadapi yang difokuskan dalam bentuk pertanyaan, tugas, dan pendapat yang harus disampaikan oleh peserta (Elfi, 2017). Dalam kegiatan diskusi tersebut, para guru dapat berbagi pengalaman dalam pemanfaatan lingkungan sekolah sebagai sumber belajar untuk mencapai hasil yang maksimal. Bagi guru yang memiliki pengalaman yang banyak akan lebih matang dan bagi guru yang masih belum berpengalaman akan memperoleh pengetahuan baru.

Keunggulan FGD adalah keterlibatan guru bersifat holistic dan komprehensif dalam semua kegiatan. Afiyanti (2008) menyatakan keunggulan FGD adalah memberikan data yang lebih banyak dan memberikan nilai tambah. Keunggulan lainnya adalah guru dapat menukar pendapat, memberi saran, tanggapan dan berbagai reaksi sosial dengan teman seprofesi sebagai peluang bagi mereka untuk meningkatkan kemampuan dan pengalaman (Waluyati, 2020). Dengan keunggulan itu Aswat (2019) menyatakan dalam penelitiannya bahwa metode FGD dapat meningkatkan kegiatan guru yang baik hingga berada pada kategori sangat baik.

\section{METODE PENELITIAN}

Penelitian ini menggunakan desain penelitian tindakan sekolah (school action research). Penelitian ini difokuskan pada penyempurnaan kegiatan pembelajaran dengan menerapkan pendekatan pembelajaran kontekstual atau contextual teaching and learning melalui focus group discussion. Pelaksanaan penelitian ini di SDN 019 Sungai Gantang Kecamatan Kempas Kabupaten Indragiri Hilir yang dimulai bulan Februari - Maret 2020. Subjek penelitian sebanyak 17 guru dengan laki-laki berjumlah 4 orang dan perempuan 13 orang. Penelitian tindakan berbentuk siklus, di dalam siklus terdapat empat tahapan atau langkah-langkah menurut Kemmis dan McTaggart dalam Arikunto (2013) meliputi perencanaan (planning), tindakan (acting), pengamatan (observating), dan refleksi (reflecting).

Teknik pengumpulan data menggunakan lembar observasi pelaksanaan kegiatan pembelajaran yang dilakukan oleh guru, dalam hal ini pembelajaran berbentuk micro teaching yang beranggotakan sesame guru. Teknik analisis data menggunakan jenis statistik deskriptif penskoran kemudian dipersentase. Kriteria atau ukuran yang digunakan ialah menentukan nilai (persentase) yang diklasifikasikan atas dasar tingkatan sebagai berikut (Depdikbud dalam Siregar, 2018): skor 5 $(81-100 \%)$ berarti baik sekali, skor $4(61-80 \%)$ berarti baik, skor $3(41-60 \%)$ berarti cukup, skor $2(21-40 \%)$ berarti kurang, dan skor $1(1-20 \%)$ berarti kurang sekali.

Indikator keberhasilan penelitian ini ditandai dengan adanya peningkatan kemampuan guru dalam menerapkan pembelajaran kontekstual dan memperoleh skor micro teaching dengan ratarata minimal $80 \%$. Diharapkan seluruh guru mampu memperoleh nilai yang baik sekali agar dapat dijadikan alternatif dalam kegiatan pembelajaran terhadap siswa.

\section{HASIL DAN PEMBAHASAN}

Penelitian diawali dengan melakukan diskusi dengan guru mengenai kegiatan penelitian terkait penerapan pembelajaran kontekstual. Peneliti menyampaikan tahapan penelitian sesuai pembelajaran kontekstual serta memberikan contoh-contoh dari masing-masing tahapan. Untuk menyempurnakan pelaksanaan dilakukan metode yakni FGD atau focus group discussion guna memperoleh kesempurnaan dalam pelaksanaan pembelajaran. Guru secara bergiliran melakukan micro teaching dalam menerapkan pembelajaran kontekstual, peneliti bertindak sebagai observer terhadap pembelajaran yang dilakukan guru. Hasil pengamatan dari pelaksanaan kegiatan ini sebagaimana terdapat dalam tabel berikut: 
Tabel 1. Kemampuan Guru dalam Menerapkan Pembelajaran Kontekstual

\begin{tabular}{lllcc}
\hline \multirow{2}{*}{ No. } & \multicolumn{2}{c}{ Kemampuan Guru Menerapkan Pembelajaran Kontekstual } & \multicolumn{2}{c}{ Rata-rata Skor } \\
& Mengonstruksi pembelajaran dengan kegiatan & (demonstrasi, & Siklus II \\
\hline 1. & eksperimen, pertanyaan, dll) & 79.41 & 83.82 \\
2. & Melakukan penyelidikan (inkuiri) & 79.41 & 85.29 \\
3. & Adanya pertanyaan (questioning) dalam kegiatan pembelajaran & 82.35 & 86.76 \\
4. & Adanya Learning Community (berpasangan, kelompok) & 77.94 & 82.35 \\
5. & Mengadakan pemodelan (modelling) dalam pembelajaran & 80.88 & 83.82 \\
6. & Melakukan refleksi pada akhir pembelajaran & 79.41 & 85.29 \\
7. & Memberikan penilaian autentik (authentic assessment) dalam proses dan & 82.35 & 83.82 \\
& akhir pembelajaran & $80.25 \%$ & $84.45 \%$ \\
\hline
\end{tabular}

Berdasarkan tabel 1 di atas diketahui bahwa kemampuan guru dalam menerapkan pembelajaran kontekstual sudah baik terlihat pada siklus I guru mampu memperoleh nilai $80.25 \%$ dengan kategori baik. Pada siklus II meningkat menjadi $84.45 \%$ yang termasuk dalam kategori baik sekali.

\section{Pembahasan}

Pada siklus I di atas, terlihat bahwa ratarata kemampuan guru dalam menerapkan pembelajaran kontekstual adalah sebesar $80.25 \%$, nilai ini adalah baik sesuai kategori penilaian pembelajaran di atas. Kemampuan paling rendah dalam menerapkan pembelajaran kontekstual adalah learning community yakni sebesar 77.94, hal ini terlihat bahwa mayoritas guru tidak menyiapkan pesertanya dalam bentuk kelompok belajar padahal pembelajaran kooperatif atau dalam bentuk pembelajaran berkelompok dapat menigkatkan kerjasama siswa serta dapat melatih kemampuan komunikasi siswa (Rosita, 2015). Adapun kemampuan guru paling tinggi adalah questiong dan authentic assessment yang keduanya memperoleh 82.35. Keterampilan bertanya harus dikuasai guru agar menciptakan pembelajaran yang efektif (Indriyani, 2015).

Adapun secara klasikal, guru yang mampu menerapkan pembelajaran kontekstual dengan kategori baik sekali berjumlah 12 orang atau sebesar $70.58 \%$ dari keseluruhan guru. Berdasarkan hasil ini baik kemampuan guru secara rata-rata maupun secara klasikal dalam menerapkan pembelajaran kontekstual belum mencapai kriteria keberhasilan yang diharapkan dimana kemampuan guru yang diharapkan adalah minimal $81 \%$ dan secara klasikal harus seluruh guru memperoleh nilai baik sekali.

Berdasarkan hasil penelitian pada siklus I tersebut, menunjukkan bahwa kemampuan guru sudah tergolong baik namun peneliti ingin standar yang lebih tinggi sesuai indikator yang diharapkan dalam penelitian ini, sehingga penelitian ini masih perlu dilanjutkan pada siklus II guna mencapai indikator keberhasilan yang telah ditetapkan dengan memperhatikan beberapa poin penting yang menjadi kelemahan dan kendala yang terjadi pada siklus I.

Tindakan pada siklus II merujuk pada refleksi siklus I dimana terdapat beberapa aspek yang perlu ditingkatkan terutama aspek learning community. Fauziddin (2016) menyatakan bahwa pembelajaran dengan kerja kelompok dapat melatih kerjasama siswa yang meliputi berbagai unsur kemampuan berinteraksi dengan teman kelompok, saling membantu, dan bertanggung jawab dalam menyelesaikan tugas kelompok.

Setelah dilakukan penelitian pada siklus II dengan mengacu pada perbaikan dari siklus I maka terjadi peningkatan yang lebih baik terhadap kemampuan guru dalam menerapkan pembelajaran kontekstual. Berdasarkan data pada tabel 1 diketahui bahwa melalui focus group discussion menjadikan rata-rata kemampuan guru dalam menerapkan pembelajaran kontekstual pada siklus II mencapai $84.45 \%$. Hasil ini sesuai dengan capaian penelitian yang dilakukan oleh Bala (2018). Selaras dengan penelitian ini juga 
dibuktikan oleh Widiyati (2019) bahwa FGD dapat meningkatkan aktivitas dan hasil belajar siswa. Di lain sisi, FGD mampu meningkatkan kemampuan guru dalam menerapkan pembelajaran dengan pendekatan saintifik (Jumino, 2019).

Secara klasikal seluruh guru mampu menerapkan pembelajaran kontekstual dengan baik sekali. Dari hasil penelitian pada siklus II ini, menunjukkan bahwa kemampuan guru dalam menerapkan pembelajaran kontekstual mengalami peningkatan yang signifikan dan mampu mencapai indikator keberhasilan yang ditetapkan. Dengan hasil ini penelitian dianggap berhasil, artinya kemampuan guru dalam menerapkan pembelajaran kontekstual dapat ditingkatkan melalui focus group discussion.

\section{SIMPULAN DAN REKOMENDASI}

Berdasarkan uraian pada hasil analisis dan pembahasan di atas, maka dapat disimpulkan bahwa penelitian dengan metode focus group discussion dapat meningkatkan kemampuan guru SDN 019 Sungai Gantang dalam menerapkan pembelajaran kontekstual. Hal ini terlihat dari rata-rata kemampuan guru pada siklus I sebesar $80.25 \%$ dengan kategori baik meningkat menjadi $84.45 \%$ dengan kategori baik sekali pada siklus II.

Rekomendasi bagi peneliti untuk dijadikan bahan penelitian selanjutnya adalah agar guru lebih memperhatikan setiap aspek dalam pembelajaran kontekstual, selain itu guru harus berusaha memahami lingkungan siswa agar materi yang disajikan betul-betul terkait dengan lingkungan sekitar siswa sehingga siswa merasa pembelajaran yang mereka lakukan bermanfaat bagi dirinya juga lingkungan.

\section{DAFTAR PUSTAKA}

Afriyanti. (2008). Focus Group Discussion (Diskusi Kelompok Terfokus) Sebagai Metode Pengumpulan Data Penelitian Kualitatif Yati. Jurnal Keperawatan Indonesia, 12 (1), 58-62.

Agung, L, S. (2015). The Development of Local Wisdom-Based Social Science Learning Model with Bengawan Solo as the Learning Source. American International Journal of Social Science, 4 (4), 51-58.
Arikunto, S. (2013). Dasar-dasar Evaluasi Pendidikan. Jakarta: Bumi Aksara.

Aswat. (2019). Efektivitas Pelaksanaan Metode Diskusi Kelompok Terpusat (Focus Group Discussion) Terhadap Motivasi Belajar IPS Murid Kelas V SD Negeri II BoneBone Kota Baubau. Jurnal PAUD, 2 (1), 1 27.

Bala, R. (2018). Peningkatan Kemampuan Guru dalam Penerapan Pembelajaran Kontekstual Melalui Focus Group Discussion (FGD). PEDAGOGIA: Jurnal Ilmu Pendidikan, 9 (2), 189-194.

Elfi, Y. (2017). Effectiveness of Methods Focus Group Discussion (FGD) Parental Communication in the Role of Adolescent Sexual Behavior in SMAN 3 Kota Cirebon Year 2016. CARE: Jurnal Ilmiah Ilmu Kesehatan, 5 (3), 418-430.

Fauziddin, M. (2016). Peningkatan Kemampuan Kerja Sama Melalui Kegiatan Kerja Kelompok pada Anak Kelompok A TK Kartika Salo Kabupaten Kampar. Jurnal PAUD Tambusai, 2 (1), 29-45.

Heldanengsih. (2020). Meningkatkan Kemampuan Guru untuk Menerapkan Pembelajaran CTL melalui In House Training (IHT). Jurnal EDUCATIO (Jurnal Pendidikan Indonesia), 6 (1), 19-23.

Hidayah, A, N., Sidik, S, A., dan Mulia, D. (2020). Penggunaan Model Pembelajaran Kontekstual dalam Meningkatkan Kemampuan Menulis Permulaan Siswa Kelas III di SKH Nurbayan 01 Kota Tangerang. Jurnal UNIK Pendidikan Luar Biasa, 5 (1), 1-20.

Indriyani, D., Djahir, Y., dan Barlian, I. (2015). Analisis Keterampilan Bertanya Guru Ilmu Pengetahuan Sosial di SMP Negeri 27 OKU. Jurnal Profit, 2 (2), 131-143.

Irwanto. (2006). Focus Group Discussion: a Simple Manual. Jakarta: Yayasan Obor.

Jumino. (2019). Meningkatkan Kemampuan Guru dalam Menerapkan Pendekatan Saintifik Melalui Supervisi Akademik dengan Pendekatan Focus Group Discussion (FGD) di SMP dalam Wilayah Binaan 
Jurnal PAJAR (Pendidikan dan Pengajaran)

Volume 5 Nomor 3 April 2021 | ISSN Cetak : 2580 - 8435 | ISSN Online : 2614 - 1337

DOI : http://dx.doi.org/10.33578/pjr.v5i4.8445

Kabupaten Bangkalan. Jurnal Koulutus, 2 (1), 144-160.

Muslich, M. (2009). KTSP: Pembelajaran Berbasis Kompetensi dan Kontekstual. Jakarta: Bumi Aksara.

Nataliya, P. (2015). Efektivitas Penggunaan Media Pembelajaran Permainan Tradisional Congklak untuk Meningkatkan Kemampuan Berhitung pada Siswa Sekolah Dasar. Jurnal Ilmiah Psikologi Terapan, 3 (2), 343-358.

Rosita, I., dan Leonard. (2015). Meningkatkan Kerjasama Siswa Melalui Pembelajaran Kooperatif Tipe Think Pair Share. Jurnal Formatif, 3 (1), 1-10.

Siregar, S. (2018). Meningkatkan Kemampuan Guru dalam Menerapkan Pembelajaran Kontekstual Melalui Focus Group Discussion (FGD) di SMK Negeri 1 Sirandorung Tahun Pelajaran 2017/2018. Nusantara (Jurnal Ilmu Pengetahuan Sosial), 5, 14-19.

Suharso, R. (2017). Pembelajaran Sejarah Lokal pada Kelas Sejarah (Model Pengembangan Bahan Ajar Sejarah Lokal Kota Kudus dalam Rangka Meningkatkan Minat Siswa pada Sejarah). Jurnal Sejarah dan Budaya, 11 (1), 95-111.

Suryani, N. (2016). Pengembangan Media Pembelajaran Sejarah Berbasis IT. Sejarah dan Budaya:Jurnal Sejarah, Budaya, dan Pengajarannya, 10 (2), 186-196.

Waluyati, M. (2020). Penerapan Focus Group Discussion (FGD) untuk Meningkatkan Kemampuan Memanfaatkan Lingkungan Sebagai Sumber Belajar. Jurnal Edutech Universitas Pendidikan Ganesha, 8 (1), 80-91.

Widiyati. (2019). Focus Group Discussion (FGD) untuk Meningkatkan Aktivitas dan Hasil Belajar Kompetensi Ketenagakerjaan Peserta Didik di SMPN 7 Purworejo. Indonesian Journal of Historical Education, 7 (2), 146-153. 